\title{
TECNOLOGIA SOCIAL NO CONTEXTO DA AGRICULTURA FAMILIAR: ANÁLISE DA REAPLICAÇÃO NO TERRITÓRIO CANTUQUIRIGUAÇU - PARANÁ
}

\author{
Elenice da Silva Carvalho ${ }^{1}$ \\ Sandra Mara Stocker Lago ${ }^{2}$
}

\section{RESUMO}

Este artigo tem como objetivo analisar os resultados da reaplicação da tecnologia social denominada "Produção Agroecológica sob o cultivo protegido (estufa), Pomar diversificado e Fonte", com os agricultores familiares nos municípios de Pinhão e Reserva do Iguaçu, no território Cantuquiriguaçu, estado do Paraná. Trata-se de um estudo de caso, com abordagem qualitativa. A pesquisa confirmou que a tecnologia social atende a todos os princípios e características referenciados pela literatura como: reaplicabilidade, transformação social, desenvolvimento participativo, contextualização local, simplicidade, baixo custo e viabilização de empreendimentos populares. As análises evidenciaram também, maior proporção de benefícios resultantes da reaplicação da tecnologia social, que em relação aos custos e falhas do processo, remetendo-se essa condição às próprias características da tecnologia social. O estudo demonstrou a importância da participação dos atores sociais no processo de reaplicação da tecnologia social e para o desenvolvimento de outras ações, a fim de fortalecer a agricultura familiar.

Palavras-chaves: atores sociais, agricultura familiar, desenvolvimento sustentável, tecnologia social, sustentabilidade.

\section{SOCIAL TECHNOLOGY IN THE CONTEXT OF FAMILY FARMING: ANALYSIS OF THE REAPLATION IN THE CANTUQUIRIGUAÇU TERRITORY - PARANÁ}

\begin{abstract}
This article aims to analyze the results of the reapplication of the social technology denominated "Agroecological Production under Protected Cultivation (greenhouse), Diversified Orchard and Source", with family farmers in the municipalities of Pinhão and Reserva do Iguaçu, in the Cantuquiriguaçu territory, state of Paraná. This is a case study, with a qualitative approach. The research confirmed that social technology meets all the principles and characteristics referred to in the literature, such as: reapplicability, social transformation, participatory development, local context, simplicity, low cost and viability of popular enterprises. The analyzes also

${ }^{1}$ Graduada em Administração (FAESO). Mestrado em Administração (UNIOESTE). E-mail: esilva.carvalho@hotmail.com

${ }^{2}$ Graduada em Administração (UNIOESTE). Mestrado em Engenharia de Produção (UFSC). Doutorado em Desenvolvimento Regional e Agronegócio (UNIOESTE). Professor do Programa de Pós-Graduação em Administração (UNIOESTE).E-mail: smstocker@uol.com.br
\end{abstract}


showed a greater proportion of benefits resulting from the reapplication of social technology, than in relation to the costs and failures of the process, referring this condition to the very characteristics of social technology. The study demonstrated the importance of the participation of social actors in the process of reapplying social technology and for the development of other actions, in order to strengthen family farming.

keywords: social actors, family farming, sustainable development, social technology, sustainability.

\section{INTRODUÇÃO}

O reconhecimento do agricultor familiar e o impacto das políticas públicas nas últimas décadas trouxeram o desenvolvimento rural para os empreendimentos familiares (GRISA; SCHNEIDER, 2015). Entretanto, além das políticas públicas, fazse necessária a adoção de estratégias eficientes que apoiem o desenvolvimento da agricultura familiar como empreendimento rural, entre elas: melhoria no processo de produção, busca de novos mercados, obtenção de crédito, melhoria da qualidade do produto, gestão do negócio (CAMPOS; CARVALHO, 2011), e ainda, aspectos sociais e ambientais que visem a melhoria da qualidade de vida do produtor rural e a destinação correta dos resíduos.

As Tecnologias Sociais (TS), que compreendem produtos, técnicas e/ou processos reaplicáveis na interação com a comunidade e criadas a partir de saberes populares ou pelo desenvolvimento científico (CARVALHO et al., 2016), apresentam-se como alternativas simples, de baixo custo e possíveis de serem apropriadas por produtores rurais familiares.

A disseminação do processo não acontece sozinha, e muito menos apenas por vontade dos agricultores. Ela é apoiada pelos atores sociais institucionais envolvidos no processo, como cooperativas, associações, instituições de assistência técnica e extensão rural (ATERs) e órgãos municipais, estaduais e federais, além das lideranças locais e regionais.

Diante disso, esta pesquisa teve como objetivo analisar os resultados da reaplicação de uma tecnologia social, denominada "Produção Agroecológica sob o cultivo protegido (estufa), Pomar diversificado e Fonte", com os agricultores familiares nos municípios de Pinhão e Reserva do Iguaçu localizados no território Cantuquiriguaçu, estado do Paraná.

A contextualização do tema se fundamenta em dois eixos principais: o primeiro trata da reaplicação da tecnologia social à agricultura familiar; e o segundo eixo aborda o papel dos atores sociais institucionais responsáveis pela reaplicação dessa tecnologia social com os agricultores na região estudada.

\section{FUNDAMENTAÇÃO TEÓRICA}

\subsection{TECNOLOGIAS SOCIAIS E AGRICULTURA FAMILIAR}

O termo e conceito da Tecnologia Social começou a ser estudado no Brasil a partir do surgimento do campo multidisciplinar dos Estudos Sociais da Ciência e Tecnologia, que permitiu o olhar multidisciplinar da educação, da sociologia, das engenharias e da economia para o tema (FRAGA, 2011). A partir de meados de 1970, o conceito de Tecnologia Social foi retomado a partir da ideia de Tecnologia 
Intermediária e associado ao conceito de Tecnologia Apropriada, remetendo a uma alternativa para a atual tecnologia convencional (DAGNINO, 2014).

De acordo com Carvalho et al. (2016), o conceito de tecnologia social está associado à criação e ao desenvolvimento de um aparato (equipamento, produto, mecanismo, métodos,) a partir de saberes populares ou por meio do conhecimento de base acadêmica e científica, para solução de problemas sociais com propostas simples, aplicáveis e de baixo custo.

Silva (2012, p. 65) destaca os princípios para o processo de desenvolvimento de uma tecnologia social, baseado nas características apresentadas pela literatura:

a) Transformação social: soluções que promovam mudança socioeconômica, social e no estilo de vida da comunidade;

b) Desenvolvimento participativo: desenvolvidas e/ou aplicadas na interação da comunidade, ou partir de saberes populares;

c) Contextualização local: a partir do contexto social, econômico ou ambiental;

d) Simplicidade;

e) Baixo custo: adaptada para produtos, processos, sistemas ou metodologias de baixo custo;

f) Reaplicabilidade: possível de ser reaplicáveis, servindo de referência para outras comunidades ou público-alvo;

g) Viabilização de empreendimentos populares: capaz de viabilizar empreendimentos populares como cooperativas, associações, agricultores familiares, incubadoras, etc.

As tecnologias sociais voltadas à agricultura familiar, que utilizam como aplicação de um processo ou método, têm seus estudos voltados principalmente para o processo de produção e cultivo de alimentos (CORDEIRO et al., 2010) e para comercialização e fornecimento desses alimentos (FRANZONI; SILVA, 2016). As tecnologias sociais aplicadas a esse grupo demonstraram melhoria da eficiência técnica ou desenvolvimento do empreendimento familiar, com aumento da capacidade de produção, melhora na qualidade do produto e alternativas para geração de renda.

Dentro desse contexto, a literatura tem demonstrado tecnologias sociais reaplicadas na agricultura familiar e que buscam manejar recursos da propriedade de forma sustentável, utilizando de preceitos agroecológicos, a exemplo da tecnologia social Quintal Produtivo (ABRANTES, 2015).

Ainda nesse sentido, a tecnologia social PAIS - Produção Agroecológica e Integrada e Sustentável, certificada pela Fundação Banco do Brasil (FBB) no ano de 2007, também teve como objetivo a produção agroecológica, por meio de agricultura sustentável e sem o uso de agrotóxicos. O sistema integra técnicas simples e priorizam o desenvolvimento do cultivo a partir de insumos internos da propriedade como: sistema de irrigação por gotejamento, utilização dos resíduos animais como matéria prima para produção de composto, diversificação da produção e a integração por meio da produção de frutas e, ao mesmo tempo, de pasto para alguns animais (FBB, 2018; CORDEIRO et al., 2010; NDIAYE, 2016; MUÑOZ, 2015; DA SILVA; DE QUEIROZ CALEMAN, 2014).

Ainda no contexto de produção sustentável, a tecnologia social Quintal Verde foi difundida no estado de Tocantins, e utiliza o Sistema Mandalla de produção. O Sistema Mandalla consiste na produção agrícola sendo bastante utilizado em pequenas propriedades rurais. O objetivo principal do sistema é diversificar as atividades agrícolas, incluindo tecnologias e metodologias de baixo custo para as comunidades (ABREU et al., 2010; LUCENA et al., 2017). 
O projeto Seda Justa, tecnologia social certificada pela FBB em 2011, adota a metodologia para o aproveitamento dos fios do bicho-da-seda por meio do comércio justo e solidário, na comunidade da Vila Rural Esperança, Paraná. O Projeto adota o conceito de comércio justo, remunerando de forma justa e digna as artesãs da comunidade, sendo que o projeto é composto apenas por mulheres, incrementando a sua renda e permitindo o acesso à tecnologia (BONILHA; SACHUK, 2011).

Cabe destacar o projeto do Biodigestor Sertanejo, desenvolvido pela ONG Diaconia, e disseminado em vários estados brasileiros em parceria com diversas instituições financiadoras e parceiras. O projeto constitui-se de grande relevância ao utilizar o aproveitamento dos dejetos animais para a produção de biogás (MATTOS; FARIAS, 2011; CARVALHO et al., 2017).

Outros dois produtos similares, que têm como objetivo a produção de biocomposto aeróbio para ser utilizado na produção de orgânicos ou melhoria das condições ambientais, são o Agro-infusor de Biocomposto (FBB, 2018) e a Fossa Séptica Biodigestora (BUGELLI; FELÍCIO, 2019).

Para fins deste estudo, aborda-se especificamente a tecnologia social de produção agroecológica denominada "Produção Agroecológica sob o cultivo protegido (estufa), Pomar diversificado e Fonte", certificado pela FBB no ano de 2013 e reaplicada com os agricultores familiares do território Cantuquiriguaçu, estado do Paraná.

\subsection{O PAPEL DOS ATORES SOCIAIS NO PROCESSO DE DESENVOLVIMENTO, IMPLANTAÇÃO E REAPLICAÇÃO DAS TECNOLOGIAS SOCIAIS}

A importância dos atores sociais no processo de desenvolvimento, implantação e reaplicação das tecnologias sociais é destacada pelo papel da comunidade, que, por meio do princípio participativo da tecnologia social e pela interação dos saberes, viabiliza o desenvolvimento sustentável no grupo em que estão inseridos.

Ainda, dentro desse grupo de atores sociais destaca-se o papel das parcerias, por meio das cooperativas, associações, instituições de assistência técnica e extensão rural, organizações não-governamentais (ONGs), órgãos governamentais municipais, estaduais e federais, movimentos sociais e outras instituições.

A questão essencial do processo de desenvolvimento, implantação e reaplicação das tecnologias sociais, volta-se, principalmente, para a emancipação dos atores sociais envolvidos, tendo como centro não só os produtores rurais e os usuários, mas, ainda, as parcerias firmadas e o envolvimento da comunidade. Nesse sentido, vale destacar a pequena quantidade de trabalhos acadêmicos que salientam a importância dos atores sociais na promoção das tecnologias sociais (FONSECA; SERAFIM, 2010; CARVALHO; LAGO, 2018).

Assim, é possível perceber uma longa lista de atores interessados no processo de produção de conhecimento inclusivo, sendo divididos em três grandes blocos: pesquisa, formação de recursos humanos e transferência de conhecimento. Nestes, de acordo com Dagnino (2014), estão inseridos também movimentos sociais, ONGs, empresas e governo.

Conforme Fonseca e Serafim (2010), existem três principais atores no processo de promoção das tecnologias sociais: o Estado, a comunidade de pesquisa e os movimentos sociais. Barboza (2011) reforça ainda que, para a sistematização, divulgação e ampliação dessas tecnologias sociais à agricultura familiar faz-se 
necessária a construção coletiva de conhecimento entre agentes de ATER públicos, agentes do meio técnico-científico acadêmico e movimentos sociais.

Conforme conceito dado à TS, em relação à participação da comunidade, pode-se ressaltar que dentro do processo de desenvolvimento e reaplicação dessas tecnologias, existem dois grupos de atores: os que promovem o desenvolvimento, sendo responsáveis pela sua reaplicação, e os beneficiados (público-alvo). A Fundação Banco do Brasil possui em seu banco de dados de tecnologias sociais certificadas o cadastro de mais de 50 tipos de públicos beneficiados pelos projetos, dentre eles estão os que se classificam com maior vulnerabilidade social ou situação de exclusão social como: agricultores familiares, assentados, catadores de material recicláveis, desempregados, famílias de baixa renda, pescadores, população carcerária, população ribeirinha, povos indígenas, idosos, quilombolas, surdos, seringueiros, entre outros (FBB, 2018).

Assim como outros autores reforçam como ponto crucial do processo da tecnologia social a participação e a interação da comunidade, Oliveira (2013) ressalta que, para promover o desenvolvimento participativo, devem ser difundidos dentro desse processo valores como a cooperação, confiança, colaboração e solidariedade.

O Estado, por meio dos órgãos das esferas municipais, estaduais e federais, possui um papel de importância na multiplicação e no processo de adoção das tecnologias sociais, por meio das políticas públicas que viabilizem esses projetos (FRANZONI; SILVA, 2016; FONSECA; SERAFIM, 2010; DE OLIVEIRA; SILVA, 2012; GAPINSKI; FREITAS, 2016). As lacunas deixadas entre o desenvolvimento tecnológico e o desenvolvimento social, podem ser supridas pela participação efetiva do poder público, responsável por aproximar os descobrimentos e avanços científicos da sociedade (FRANZONI; SILVA, 2016).

As universidades, centros de pesquisas e o meio acadêmico em geral, possuem um papel de grande relevância, no que diz respeito, principalmente, ao desenvolvimento e adaptação dessas tecnologias sociais, unindo o conhecimento científico à sabedoria popular, analisados nos estudos de Almeida (2010), Caldas et al. (2007), Dias (2016), Klossowski, Freitas e Freitas (2016), Silva (2012) e Sousa e Rufino (2017).

Para que a universidade crie vínculos com a sociedade é necessária a criação de um ambiente institucional que reforce o caráter indissociável da extensão, do ensino e da pesquisa. Essa articulação entre pesquisa e extensão pode trazer contribuições significativas para a promoção das tecnologias sociais, reforçando além de tudo a relação universidade-comunidade (ALMEIDA, 2010). Nesse caso, o profissional capaz de atuar com tecnologias sociais seria capaz de colaborar por meio das atividades de ensino, pesquisa e extensão para a solução de problemas que atingem milhões de pessoas (FONSECA; SERAFIM, 2010).

As cooperativas ou associações apresentam-se também como os principais parceiros no processo implantação e reaplicação das tecnologias sociais. Os estudos de Arakaki et al. (2016), de Oliveira e Silva (2012) e Mourão (2017) destacaram a importância do cooperativismo e de empreendimentos coletivos para esse processo.

De acordo com Oliveira (2013) as experiências coletivas estimulam a aprendizagem e o processo de inovação; sendo assim, empreendimentos coletivos possibilitam a construção da cidadania e o enfrentamento de problemas globais, por meio da ação econômica e social local.

Nesse mesmo sentido, alguns estudos destacaram a importância da instituição SEBRAE - Serviço Brasileiro de Apoio às Micro e Pequenas Empresas como ator chave no processo de disseminação das tecnologias sociais no Brasil, no 
que se refere aos projetos de tecnologias sociais relacionados ao Programa PAIS Produção Agroecológica Integrada e Sustentável (CORDEIRO et al., 2010; NDIAYE, 2016).

Por sua vez, Faria (2012) ressalta a importância das instituições de assistência técnica e extensão rural (ATERs), para que o processo de inovação chegue até o agricultor, por meio dos modelos difusionista e construtivista, neste último reforçando a participação dos agricultores e a valorização do conhecimento local como estratégias para o desenvolvimento rural. Embora haja avanços em relação à participação dos atores e da aceitação e incorporação do saber tradicional nas pesquisas agropecuárias, a aproximação entre técnicos e agricultores é o ponto crucial dessa análise (PERERA, 2009).

Vale destacar, outra importante instituição que se tornou referência na promoção das tecnologias sociais, tendo um dos principais bancos de dados de tecnologias socais no Brasil. A Fundação Banco do Brasil, por meio do Banco de Tecnologias Sociais, apresenta soluções para demandas sociais desenvolvidas por instituições de todo o país (FBB, 2018).

\section{MÉTODO}

Esta pesquisa trata-se de um estudo de caso, com abordagem qualitativa. Em relação aos objetivos, ela se classifica como exploratória e descritiva. Conforme Gil (2008), o estudo de caso caracteriza-se pelo estudo aprofundado de um ou poucos objetos, permitindo amplo conhecimento e detalhado sobre o assunto estudado.

A pesquisa consiste em duas fases principais: a primeira consiste na análise da reaplicação da tecnologia social pelos agricultores familiares nos municípios de Pinhão e Reserva do Iguaçu, do território Cantuquiriguaçu, Paraná; e a segunda fase que consiste na identificação dos atores sociais institucionais responsáveis pela reaplicação dessa tecnologia, seu papel e as relações estabelecidas por esses atores na região de estudo.

O estudo foi desenvolvido a partir da tecnologia social denominada "Produção Agroecológica sob o cultivo protegido (estufa), Pomar diversificado e Fonte" reaplicada com os agricultores familiares dessa região.

O território Cantuquiriguaçu está localizado no terceiro planalto paranaense e corresponde a uma área de $7 \%$ do estado. O território é constituído por 20 municípios do Médio Centro Oeste do Paraná: Campo Bonito, Candói, Cantagalo, Catanduvas, Diamante do Sul, Espigão Alto do Iguaçu, Foz do Jordão, Goioxim, Guaraniaçu, Ibema, Laranjeiras do Sul, Marquinho, Nova Laranjeiras, Pinhão, Porto Barreiro, Quedas do Iguaçu, Reserva do Iguaçu, Rio Bonito do Iguaçu, Três Barras do Paraná e Virmond (IPARDES, 2007).

Para este estudo, a amostra de pesquisa limitou-se aos agricultores familiares dos principais municípios onde foi implementada a tecnologia social, Reserva do Iguaçu e Pinhão, e instituições envolvidas nesse processo: sete agricultores familiares dos municípios de Reserva do Iguaçu e Pinhão; duas Cooperativas; uma Associação; uma Instituição de Assistência Técnica e Extensão Rural e outras instituições. A escolha dos municípios justifica-se por serem os primeiros a implementarem a tecnologia social, servindo de referência para outras reaplicações.

Optou-se também pela utilização de entrevista semiestruturada aos agricultores e atores sociais institucionais identificados no estudo. Dessa forma, como a pesquisa foi realizada em campo, o pesquisador teve mais liberdade para conduzir a conversação e explorar mais aspectos pertinentes à pesquisa. 
Os questionários foram aplicados de maneira a responder aos objetivos da pesquisa: análise da reaplicação da tecnologia social, atendimento aos seus princípios, custos, benefícios e outras externalidades de sua reaplicação e a relação entre os atores sociais institucionais. As entrevistas e visitas às propriedades rurais foram realizadas entre os meses de outubro de 2018 e janeiro de 2019

\section{RESULTADOS E DISCUSSÕES}

\subsection{TECNOLOGIA SOCIAL "PRODUÇÃO AGROECOLÓGICA SOB O CULTIVO PROTEGIDO (ESTUFA), POMAR DIVERSIFICADO E FONTE”}

A tecnologia social denominada "Produção Agroecológica sob o cultivo protegido (estufa), Pomar diversificado e Fonte" foi o nome dado à tecnologia social e certificada pela Fundação Banco do Brasil em 2013, tendo como responsável a Associação dos Municípios do Cantuquiriguaçu. A sua reaplicação alcança mais de 100 agricultores dos municípios de Reserva do Iguaçu, Pinhão, Goioxim, Foz do Jordão, Laranjeiras do Sul, Guaraniaçu, Quedas do Iguaçu e Espigão Alto do Iguaçu do território Cantu.

A tecnologia foi desenvolvida pelo SEBRAE em parceria com o município de Reserva do Iguaçu, onde foi instalada uma estufa por família nas comunidades de Santa Luzia e Faxinal dos Soares, resolvendo problemas em relação à qualidade dos produtos, segurança alimentar e geração de renda. O SEBRAE foi o principal incentivador e agente fomentador do projeto, entretanto, obteve parcerias locais como prefeituras municipais, EMATER, cooperativas e associações de agricultores familiares.

A tecnologia social refere-se à produção agroecológica em estufa, integrada ao pomar diversificado e irrigação com proteção da fonte. O Sistema de Produção Agroecológica Integrada (PAIS), que é um sistema produtivo que exclui o uso de fertilizantes sintéticos e agroquímicos, serviu de inspiração para a instalação e proliferação das estufas. No sistema PAIS tradicional a horta é circular, possui um galinheiro no centro e os canteiros são irrigados por tubo de gotejamento. Neste caso, o galinheiro foi substituído por uma estufa (SEBRAE, 2012).

A construção da estufa destaca-se por criar um ambiente adequado ao cultivo de diversas espécies de plantas, que exijam desde uma temperatura mais elevada e até mesmo temperaturas mais amenas. Além disso, o ponto chave do projeto é a inclinação e a forma de colocação das tesouras de madeira, possibilitando a implantação em terrenos com declividade até $20 \%$, sem necessidade de fazer terraplenagem (FBB, 2018).

A construção da estufa é realizada de maneira coletiva (Figura 1), com a ajuda de outros agricultores, um técnico da prefeitura ou órgão estadual, e outras instituições parceiras, sendo que os serviços de construção e a madeira devem ser de responsabilidade do produtor (FBB, 2018).

$O$ processo de formação profissional é realizado por meio de encontros junto à equipe técnica, normalmente, acompanhados por consultores do SEBRAE e/ou outro órgão. Além da estufa, a proposta se dá com a implantação de um pomar orgânico irrigado, com aproximadamente 50 mudas.

Desde o início da implantação da tecnologia social até sua reaplicação em outras comunidades e produtores no território Cantuquiriguaçu, a tecnologia pode ser aperfeiçoada, dessa forma, existem diferentes tamanhos de estufas de acordo com o projeto, plantio e realidades de cada produtor rural e comunidade (FBB, 2013; SEBRAE, 2012). 
Figura 1 - Construção coletiva da estufa

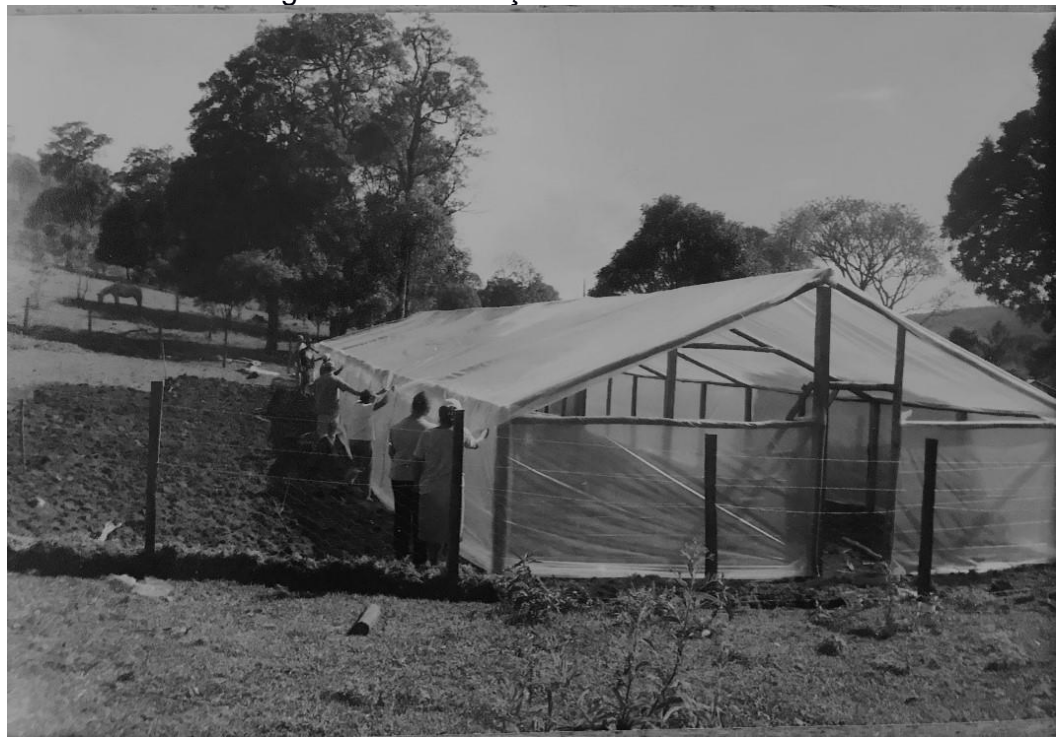

Fonte: Arquivo de agricultor entrevistado (2012).

O processo de irrigação é realizado com tubo de gotejamento e a fonte precisa ser protegida para que não entupa o sistema de filtragem, que consiste na colocação de um dreno, localizada com uma forquilha de pessegueiro e depois lacrada com argamassa. Devido ao excesso de matéria orgânica no solo, recomenda-se a aplicação de calcário num raio de $15 \mathrm{~m}$, com a finalidade de melhorar o ph acima de 5,5 e não desenvolver algas (SEBRAE, 2012).

O envolvimento da comunidade começa com a sensibilização nas propriedades que já implementaram o projeto, por meio dos depoimentos dos agricultores. Para o projeto, além do material básico, que pode ser adquirido em lojas de materiais de construção, contempla a formação básica teórica e prática para o grupo de agricultores, técnicos e multiplicadores; veículos para deslocamento até os agricultores cedidos pelos parceiros locais; financiador com recursos reembolsáveis ou não (SEBRAE, 2012).

Em relação aos mercados consumidores, nos municípios onde a estufa foi implementada, a produção foi destinada aos programas governamentais PAA Programa de Aquisição de Alimentos e o PNAE - Programa Nacional de Alimentação Escolar. O excedente de produção pode ser comercializado em parceria com as cooperativas locais e regionais (SEBRAE, 2012).

A Figura 2 mostra o modelo de estufa implementado em uma das propriedades rurais do território Cantuquiriguaçu. 
Figura 2 - Modelo de Estufa

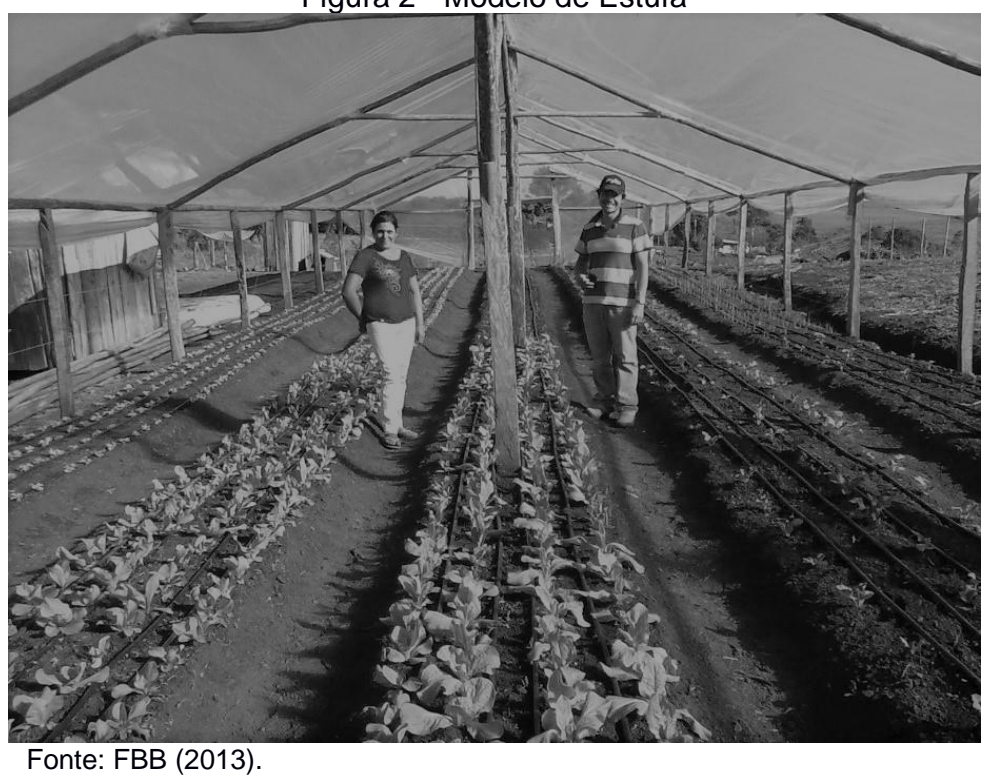

A tecnologia social se caracteriza com baixo impacto ambiental e se concentra na produção em pequenas áreas férteis. Além disso, a intenção é reduzir a pressão dos agricultores em avançar em áreas de preservação permanente (APPs) e reservas legais, sem recorrer ao uso extensivo de áreas ou utilização de agrotóxicos e outros agroquímicos.

\subsection{PRINCÍPIOS E CARACTERÍSTICAS DA TECNOLOGIA SOCIAL}

Dentre as características da TS, a reaplicabilidade foi um dos fatores principais observados no projeto. Foi considerada a possibilidade do projeto implementado na comunidade de Santa Luzia na cidade de Reserva do Iguaçu ter servido de referência para outras propriedades e outros munícipios, a partir de um processo de transferência de conhecimento e difusão da tecnologia. Ainda, outro fator de relevância, foi a disponibilização da documentação do projeto no site da Fundação Banco de Brasil, que também serve de referência para reaplicabilidade em outras localidades.

Além disso, durante os anos, o projeto foi alterado ou adaptado de acordo com a realidade local de cada produtor, como o tamanho da estufa, da caixa d'água e outros acessórios que puderam ser implementados para a melhoria da produtividade.

A possibilidade de fácil reaplicabilidade, pode estar associada a outra característica da TS, que é a simplicidade. O projeto se destaca pela utilização de materiais disponíveis em armazéns, pela simples montagem e não requerendo de grandes aparatos para a implementação, embora 0 treinamento e 0 acompanhamento técnico para a montagem das estufas sejam essenciais para possibilitar a reaplicação da tecnologia.

Outra característica importante, o baixo custo, pela possibilidade de retirada da madeira utilizada diretamente da propriedade do agricultor e pela 
possibilidade de financiamento pelo PRONAF, o que são considerados fatores de sucesso da tecnologia social apresentada.

A transformação social promovida pela tecnologia possibilitou, ainda, mudanças no contexto social, econômico e ambiental nas comunidade em que foram implementadas. O contexto econômico se caracterizou principalmente pelo incremento da renda dos agricultores, aumento da lucratividade, ampliação da produção, melhoria da qualidade dos produtos, permitindo assim a garantia de venda pelo PNAE e busca de novos mercados consumidores. O contexto social trouxe aspectos referentes à melhoria da qualidade de vida dos agricultores, o empoderamento das mulheres agricultoras, sentimento de orgulho e de pertencimento ao campo. Já o contexto ambiental se referiu principalmente ao não uso de agroquímicos com a certificação orgânica da produção, a proteção das nascentes e a possibilidade do uso de biofertilizantes.

A tecnologia social foi construída e adaptada a partir do Sistema de Produção Agroecológica Integrada (PAIS), juntamente com o saber popular e conhecimento específico do técnico em agropecuária do SEBRAE, proporcionando o desenvolvimento participativo construído no projeto junto com outros agricultores e o envolvimento de outras instituições. A participação ativa das comunidades possibilitou a interação entre o saber popular e o conhecimento técnico do projeto e das outras instituições, possibilitando tornarem-se autonônomos em sua manutenção e uso dos recursos e gestão.

O contexto do território Cantuquiriguaçu e realidade dos agricultores locais permitiu a construção da tecnologia social, respeitando a característica referente à contextualização local. A forma como a tecnologia social foi implementada e reaplicada, utilizando linguagem apropriada aos agricultores por meio de práticas como dias de campo para disseminar o conhecimento e as condições adaptadas à realidade local, demonstra o atendimento ao princípio da contextualização local.

A última característica e princípio da TS analisada refere-se à viabilização de empreendimentos populares como cooperativas, associações ou incubadoras. Nesse sentido, a tecnologia social atende a esse princípio com base no fortalecimento e criação das cooperativas, associações e grupos de mulheres nos municípios pesquisados de Pinhão e Reserva do Iguaçu: Cooperativa da Agricultura Familiar de Pinhão - COOFAPI; Associação Institucional dos Produtores Orgânicos de Pinhão - ECOPINHÃO, criada a partir dos produtores certificados pelo projeto da tecnologia social; a Cooperativa da Agricultura Familiar de Reserva do Iguaçu COOPAFI; além do grupo de mulheres viabilizado pela EMATER, que visa a promover a inclusão da mulher.

Assim, por meio da análise realizada e conforme Silva (2012), confirmam-se as características e princípios da tecnologia social "Produção Agroecológica sob o cultivo protegido (estufa), Pomar diversificado e Fonte" reaplicada no território Cantuquiriguaçu.

\subsection{BENEFÍCIOS E CUSTOS DA REAPLICAÇÃO DA TECNOLOGIA SOCIAL NO TERRITÓRIO CANTUQUIRIGUAÇU}

A identificação dos benefícios proporcionados pela implantação da Tecnologia Social (estufa) aos produtores rurais se deu por meio das entrevistas com os agricultores e alguns atores sociais institucionais. Vale ressaltar que ficou evidenciado, mesmo com os problemas enfrentados pelos agricultores após alguns anos de implantação do projeto, maior proporção de benefícios resultantes do processo de reaplicação da tecnologia social do que em relação aos custos. Esta condição remete-se às próprias características da tecnologia social como 
transformação social, desenvolvimento participativo, contextualização local, simplicidade, baixo custo, reaplicabilidade e viabilização de empreendimentos populares

Em suma, o Quadro 1 demonstra um resumo dos principais benefícios proporcionados aos produtores na reaplicação da tecnologia social.

Quadro 1 - Principais benefícios proporcionados pela tecnologia social

\begin{tabular}{|l|l|}
\hline $\begin{array}{l}\text { Dimensão } \\
\text { econômica e e } \\
\text { financeira }\end{array}$ & $\begin{array}{l}\text { Baixo custo para implementar o projeto, possibilidade de financiamento, } \\
\text { diversificação da produção, aumento da renda, aumento da lucratividade, } \\
\text { criação de empreendimento coletivo, melhoria da qualidade dos produtos, } \\
\text { garantia de venda dos produtos aos mercados, certificação dos produtos, } \\
\text { aumento da produtividade, qualidade na montagem do projeto, gestão } \\
\text { financeira }\end{array}$ \\
\hline $\begin{array}{l}\text { Dimensão } \\
\text { Social }\end{array}$ & $\begin{array}{l}\text { Cooperação, empoderamento feminino, melhoria da qualidade de vida, } \\
\text { satisfação pessoal, inclusão do trabalho de mulheres e jovens no campo, } \\
\text { flexibilidade do tempo, diversidade, sentimento de orgulho }\end{array}$ \\
\hline $\begin{array}{l}\text { Dimensão } \\
\text { Ambiental }\end{array}$ & $\begin{array}{l}\text { Não uso de agrotóxicos, proteção das nascentes de água, uso de } \\
\text { biofertilizantes }\end{array}$ \\
\hline
\end{tabular}

Fonte: Resultados da pesquisa (2019).

Os agricultores mencionaram a identificação desses benefícios, principalmente, nos primeiros anos de implantação do projeto, sendo o benefício econômico e financeiro um dos primeiros aspectos apontados pelos entrevistados.

Embora para alguns agricultores o custo de implementação do projeto foi tido como alto, devido condições precárias da propriedade, a maior parte das propriedades e famílias enxergam como benefício o baixo custo do projeto, comparado a outras estufas e projetos comerciais, e a possibilidade de financiamento por meio PRONAF - Programa Nacional de Fortalecimento da Agricultura Familiar. Entre os agricultores entrevistados $70 \%$ financiaram o projeto com recursos próprios ou com reembolso.

O PRONAF ainda vem se consolidando com uma das principais políticas públicas de apoio ao agricultor familiar no meio rural brasileiro desde que foi criado o programa, considerando o crescimento e o número de beneficiados atendidos. $\mathrm{O}$ crédito mais barato colabora ainda para elevar a produção desses agricultores e contribuir para o desenvolvimento sustentável (AQUINO; SCHNEIDER, 2015).

A implementação da estufa trouxe melhoria para a qualidade dos produtos. Por serem cultivados em um ambiente protegido, possibilita maior controle das intempéries climáticas como temperatura, umidade, ventos, chuvas e geadas. Nesse sentido, as plantas cultivadas nas estufas têm menos incidências de pragas.

Em consequência disso, o incremento da renda pela venda dos produtos produzidos pela estufa, inicialmente com a cultura do tomate e depois por outras culturas, e ainda, pela garantia da comercialização desses produtos por meio do PNAE - Programa Nacional de Alimentação Escolar, foram os principais pontos citados principalmente pelos agricultores. Com isso, percebe-se a inclusão do pequeno produtor na cadeia produtiva no território Cantuquiriguaçu e a possibilidade de busca de novos mercados.

De acordo com Gregolin et al. (2017) o montante médio anual repassado para as prefeituras do território do Cantuquiriguaçu foi de aproximadamente 2,8 milhões de reais, sendo que o município de Pinhão e Quedas do Iguaçu estiveram entre os municípios que mais receberam recursos do FNDE para investimento em 
alimentação escolar. Entretanto, estes municípios não apresentaram o melhor desempenho no que se refere à compra da agricultura familiar no território.

Outro fator mencionado foi a certificação orgânica do processo produtivo dos produtos cultivados nas estufas. A certificação ocorreu junto com a implantação do projeto, que previu a certificação por parte dos produtores. Embora os agricultores ainda tivessem tido custo no processo, a contrapartida de $50 \%$ ou $70 \%$ financiada pelo SEBRAE permitiu aos agricultores facilidade no acesso à certificação orgânica.

A diversificação da produção, embora já seja uma característica comum da agricultura familiar, foi um dos benefícios e possibilidades verificados pela implantação da estufa nas propriedades. Além da variedade de produtos produzidos na estufa como: tomate, pepino, brócolis, repolho, beterraba e outros tipos de olerícolas, o trabalho na estufa permite ainda flexibilidade para manter outras atividades das propriedades como criação de aves, gado de corte e leite e porcos, e ainda a produção de outros grãos ou a produção agroindustrial.

De acordo com Schneider (2010) a diversificação da produção amplia as alternativas para os agricultores para inserção dos produtos no mercado, reduzindo a sazonalidade e estagnação da renda. Ainda nesse sentido, essa diversificação propõe mudanças na paisagem e no ambiente da propriedade como novos tipos de manejos, uso de plantas, animais e do espaço agrícola.

Outro fator importante foi a viabilidade e criação de empreendimentos coletivos como cooperativas e associações. O projeto proporcionou de forma direta ou indireta, ao longo dos anos desde a sua implantação nas propriedades rurais o estímulo a criação de associações, cooperativas, ou o desenvolvimento dos grupos que já existiam.

No município de Pinhão, os agricultores se organizaram para alavancar a Associação dos Produtores Orgânicos de Pinhão - ECOPINHÃO, tendo início a partir da necessidade do grupo de orgânicos certificados, para se organizarem em relação às compras conjuntas de insumos e novos projetos.

O desenvolvimento do grupo de mulheres agricultoras do município de Pinhão também foi citado como uma conquista a partir da implantação da tecnologia social, e também, as cooperativas de agricultura familiar COOFAPI - Cooperativa da Agricultura Familiar de Pinhão e COOPAFI - Cooperativa da Agricultura Familiar de Reserva do Iguaçu.

A capacidade de viabilização de empreendimentos populares e coletivos como cooperativas, associações, mutirões, assentamentos de reforma agrária e incubadoras é um dos princípios e características da tecnologia social já ressaltados pela literatura (DAGNINO, 2011; NOVAES; DIAS, 2010; SILVA, 2012).

$O$ projeto ainda trouxe outras externalidades para as comunidades onde foi implementado, ou seja, benefícios na dimensão social como a cooperação e ajuda mútua, o empoderamento feminino, inclusão do trabalho de mulheres e jovens no campo, flexibilidade do tempo e do trabalho, satisfação pessoal e melhoria da qualidade de vida.

A inclusão do trabalho da mulher na agricultura e, por consequência disso, o empoderamento feminino foram fatores relevantes e perceptíveis no projeto. Este fator foi relevante e verificado nas propriedades, visto que a maior parte dos trabalhos realizados nas estufas são das mulheres agricultoras. A produção de verduras e legumes é um trabalho menos árduo para as mulheres, comparado ao plantio de grãos, por exemplo, que requer maior preparo do solo e em área de maior plantio.

A cooperação e a ajuda mútua foram benefícios trazidos pelo projeto, mas que sempre fez parte da vida dos agricultores entrevistados. A ajuda mútua dos 
vizinhos e a construção coletiva do projeto também foi citado pelos agricultores como um dos pontos fortes do projeto, com isso a estufa pode ser levantada em média de 3 a 5 dias em algumas propriedades.

O princípio participativo e a construção coletiva da tecnologia social são destacados pelos autores na literatura como um dos grandes diferenciais da tecnologia social perante a tecnologia convencional (DAGNINO, 2010; FREITAS; SEGATTO, 2014; ITS BRASIL, 2007; SILVA, 2012). Rodrigues e Barbieri (2008) ressaltam que os beneficiários das tecnologias sociais, não se caracterizam apenas como simples usuários de soluções produzidas por equipes especializadas, como ocorre com outras tecnologias convencionais.

A dimensão ambiental foi citada pelos entrevistados ou evidenciada como benefícios do processo de implantação da tecnologia social por meio da proteção da nascente de água da propriedade, o não uso de agroquímicos industriais e ainda, pelo uso de biofertilizantes, utilizado pelos agricultores como alternativa à adubação química.

A análise dos custos da reaplicação da tecnologia social pelos agricultores familiares se deu mediante os dados obtidos nas entrevistas realizadas pelos atores institucionais. Esta análise inclui, além dos aspectos econômicos (custos tangíveis), outros custos intangíveis como falhas, dificuldades e desafios no processo de reaplicação dessa tecnologia social.

O Quadro 2 demonstra um resumo dos custos, dificuldades e desafios no processo da reaplicação da tecnologia social.

Quadro 2 - Principais custos, dificuldades e desafios proporcionados pela TS

\begin{tabular}{|l|l|}
\hline Custo tangível & $\begin{array}{l}\text { Custo de implantação, transporte dos produtos, custo de } \\
\text { manutenção, certificação orgânica, perda de produção. }\end{array}$ \\
\hline Custo intangível & $\begin{array}{l}\text { Ausência de apoio técnico pós-projeto, heterogeneidade e conflito } \\
\text { de interesses entre os atores sociais, oportunismo. }\end{array}$ \\
\hline $\begin{array}{l}\text { Outras dificuldades e } \\
\text { desafios }\end{array}$ & $\begin{array}{l}\text { Permanência do jovem no campo, ausência de meio de transporte } \\
\text { próprio e adequado para os produtos, melhoria no processo } \\
\text { produtivo. }\end{array}$ \\
\hline
\end{tabular}

Fonte: Resultados da pesquisa (2019).

Um dos fatores citados foi em relação à perda de produção, principalmente a do tomate, sendo o principal produto produzido na estufa. Alguns agricultores entrevistados mencionaram que a perda se dava principalmente durante o transporte dos produtos.

Outro problema ressaltado pelos agricultores foi em relação à manutenção do projeto ao longo dos anos. Embora o custo de manutenção do projeto não seja alto, as madeiras, assim com o plástico de cobertura das estufas devem ser trocados em algum momento.

O custo referente ao transporte de produtos foi mencionado por alguns produtores. As estradas rurais onde estão localizadas as comunidades visitadas são precárias e as vias de acesso não possuem qualquer tipo de pavimentação ou calçamento. A localização de algumas propriedades em relação ao acesso às vias pavimentadas é em torno $6 \mathrm{~km}$ de distância e outras até $20 \mathrm{~km}$ de distância, além disso, essa dificuldade de acesso se sobressai em dias de chuva.

Essa dificuldade é apontada no estudo de Gregolin et al. (2017), em que ressalta a importância de uma ação mais estruturada do poder público no território do Cantuquiriguaçu, que minimize a dificuldade de transporte dos agricultores na entrega dos alimentos da alimentação escolar.

Um fator de grande relevância mencionado por vários produtores, foi em relação à ausência de apoio técnico e acompanhamento das instituições parceiras 
para continuidade dos projetos e manutenção das estufas. Mesmo sendo mencionado a relação existente entre algumas instituições como SEBRAE, EMATER e cooperativas, na continuidade do projeto como a certificação, 0 apoio às associações criadas, visitas às propriedades e cursos de formação, foi apontado por alguns agricultores a ausência de apoio técnico após implantação do projeto, em relação à manutenção da estufa, possibilidades de melhorias ou do próprio processo de produção orgânica.

Este fator também foi apontado em pesquisa realizada por Balem, Alves e Schmeling (2018) na produção de orgânicos no município de Santa Maria, Rio Grande do Sul. Destacou-se a falta de apoio técnico para produção orgânica e necessidade de uma equipe técnica extensionista maior e mais qualificada para atender aos agricultores para atuarem no mercado agroecológico.

A heterogeneidade e conflito de interesses entre todos os atores envolvidos no processo de reaplicação da tecnologia e o oportunismo foram observados durante as entrevistas, tanto pelos agricultores, quanto por alguns dos atores entrevistados.

A adequação das tecnologias e ferramentas utilizadas na produção foram apontadas pelos agricultores como possibilidade de melhorias no processo produtivo e da estufa. Embora esse equipamento tenha um custo relativamente pequeno, a maioria dos agricutores não conseguem recurso ou planejamento para sua aquisição. A maior dificuldade para se conseguir essas melhorias seria em relação ao próprio planejamento e financiamento. Entretanto, para que se consiga todas essas melhorias, a cooperação seria extremamente importante tanto no auxílio ao planejamento financeiro desses agricultores, quanto para contrapartida desses materiais.

Ressalta-se a desistência de muitos agricultores na continuidade do projeto desde a sua implantação. Entretanto, conforme entrevistas realizadas, não foi possível estimar precisamente o quantitativo de agricultores que desistiram do projeto. De acordo com a EMATER, estima-se que aproximadamente 30\% (trinta por cento) desses agricutores não deram continuidade ao projeto. Esse fator pode estar relacionado aos custos, dificuldades e desafios mencionados.

\subsection{ATORES SOCIAIS INSTITUCIONAIS E SEU PAPEL NA REAPLICAÇÃO DA TECNOLOGIA SOCIAL}

Observa-se que os atores sociais institucionais analisados neste estudo, sendo o SEBRAE, as cooperativas COOPAFI e COOFAPI, a EMATER do município de Pinhão, a Associação Institucional dos Produtores Orgânicos de Pinhão ECOPINHÃO, as prefeituras de Reserva do Iguaçu e Pinhão e a Associação dos Municípios do Cantuquiriguaçu, possuíram um papel de destaque na reaplicação da tecnologia social.

Muito embora a Associação dos Municípios do Cantuquiriguaçu tenha cedido o nome para a certificação da tecnologia social junto à Fundação Banco do Brasil, a relação existente entre outros atores e para as efetivas ações para o sucesso do projeto foi muito pequena. A representação dos municípios de Pinhão e Reserva do Iguaçu se deu diretamente pelas suas secretarias de agricultura.

Vale destacar que, como desenvolvedor do projeto, o SEBRAE manteve vínculo com todos os atores sociais, incluindo os agricultores familiares, quer na forma de consultoria, quer em relação às certificações de produção orgânica, possuindo um papel de mediador entre os outros atores durante o processo de reaplicação da tecnologia social. 
Ainda nesse sentido, conforme verifica-se na Figura 3 , destaca-se a EMATER do muncípio de Pinhão e as cooperativas COOPAFI e COOFAPI como importantes atores no processo de reaplicação da tecnologia social nos dois municípios e ainda, elos entre os agricultores e outras instituições.

Cabe destacar que o papel de mediador do SEBRAE possibilitou o acesso e inserção dos agricultores aos importantes atores EMATER e Cooperativas, permitindo que a relação entre eles permanecesse forte mesmo após os sete anos de reaplicação da tecnologia social. O mesmo foi percebido em pesquisa realizada por Campos e Schmitt (2017), em que a relação estabelecida com os mediadores desencadeou um processo rico de inovação institucional.

Entretanto, percebe-se a importância das relações dos laços fracos, ou seja, das instituições como Associação dos Municípios do Cantuquiriguaçu e das Secretarias Municipais de Educação, que foram importantes para reaplicação da tecnologia social e o acesso a políticas públicas. De acordo com Granoveter (1983), embora os laços fracos apresentem vínculo com pouca frequência nos contatos, ele oferece acesso a recursos e informações, pois conectam a vários outros grupos ou atores.

Figura 3 - Representação das relações entre os atores sociais responsáveis pela reaplicação da TS

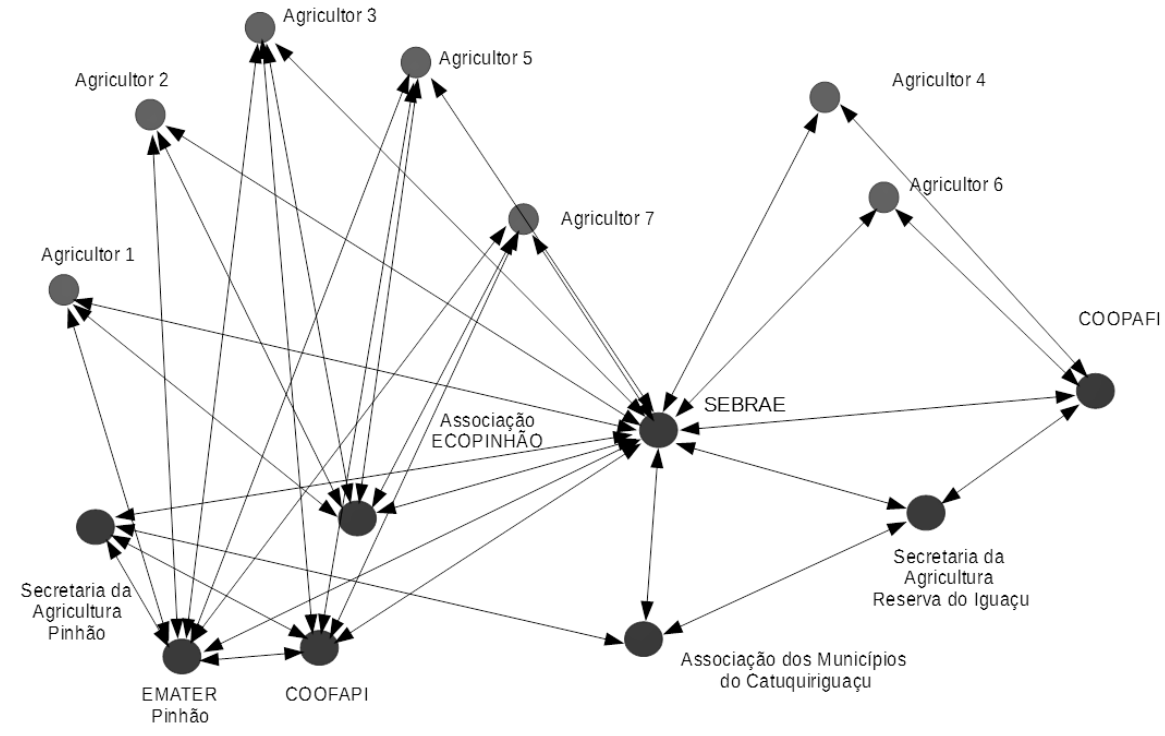

Fonte: Elaboração própria (2019).

A característica de atuação em rede de relacionamento, pode possibilitar melhor organização e fortalecimento de cada ator em relação a sua posição, alavancando ações no desenvolvimento de projetos de tecnologia social. 


\section{CONSIDERAÇÕES FINAIS}

Esta pesquisa teve como objetivo analisar os resultados da reaplicação da tecnologia social de produção agroecológica denominada "Produção Agroecológica sob o cultivo protegido (estufa), Pomar diversificado e Fonte" com os agricultores familiares no território Cantuquiriguaçu, no estado do Paraná.

Com base nas análises apresentadas, resultados das entrevistas realizadas com os agricultores familiares e alguns atores sociais institucionais, confirmou-se que a tecnologia social atende a todas as características e princípios conforme apresentado por Silva (2012). Esses resultados reafirmam a certificação dada em 2013 pela Fundação Banco do Brasil ao projeto da tecnologia social de produção agroecológica objeto desse estudo. Conforme Rodrigues e Barbieri (2008) são esses princípios da TS que ressaltam a importância para que o processo de apredizagem e a participação da comunidade caminhem juntos.

Outro fator evidenciado que remete aos próprios princípios da tecnologia social, foi em relação à presença de maior proporção de benefícios de que aos custos, resultantes da reaplicação da tecnologia social. Esse dados corroboram com as pesquisas de Carvalho et al. (2017), Franzoni e Silva (2016), Muñoz (2015), que demonstram os benefícios de tecnologias sociais aplicadas à agricultura familiar.

Esses benefícios não estão voltados apenas para os indivíduos que se apropriaram da TS, nesse caso os agricultores familiares, mas transferem-se à comunidade local, a outros agentes e ao próprio meio ambiente.

A pesquisa apontou que, mesmo após os sete anos de implantação dos projetos da tecnologia social, a melhoria em algumas comunidades, ainda que tímida (pequena) e mesmo com a desistência de muitos agricultores na continuidade do projeto, trouxe externalidades positivas como: a cooperação e ajuda mútua, o empoderamento feminino, inclusão do trabalho de mulheres e jovens no campo, flexibilidade do tempo e do trabalho, satisfação pessoal e melhoria da qualidade de vida.

Vale ressaltar que, a desistência desses agricultores em relação à continuidade e manutenção do projeto se deu por diversos fatores como os próprios custos e desafios apontados no processo, bem como ausência de políticas públicas, desestímulo à produção orgânica, foco de produção voltado para outros cultivos. Também, a adoção de formas individualizadas e desarticuladas dos agricultores, trouxe a desistência e abandono do projeto em algumas propriedades.

Entretanto, observou-se que, entre os agricultores entrevistados que deram continuidade ao projeto, sua ligação entre os atores sociais institucionais e sua forma de organização local e regional, trouxe motivação para que se mantivessem estruturados para a continuidade do projeto da tecnologia social.

Conforme Zylbersztajn (2005), quando se trata de agricultura familiar, ações isoladas e individuais, dificilmente vão dispor de todos os recursos e condições para atender demandas de inovação ou para o desenvolvimento do pequeno produtor, exigindo que estes indivíduos sejam apoiados por outros indivíduos e organizações para atingir o resultado necessário. Nesse sentido, as ações coletivas e os atores sociais, bem como os laços e interdependências formados por esses atores são de fundamental importância para o sistema e economia agroalimentar.

É possível auferir, dentro desse contexto, que o sucesso de um projeto de tecnologia social ou de outro projeto que alavanque a agricultura familiar, está também condicionado ao fortalecimento e ligação que esses atores sociais possuem entre si. 
Outro fator, observado na pesquisa, foi em relação à possibilidade de reaplicação da tecnologia social em outros municípios do território Cantuquiriguaçu. Entretanto, o que observou-se é que a tentativa de reaplicação em outros munícipios não tiveram o mesmo êxito como nos municípios pesquisados, visto que em alguns casos não houve a participação da comunidade. Esse fator pode ser justificado pela ausência de atores sociais insticionais no projeto de reaplicação nessas localidades ou articulação entre esses atores.

Mesmo com a presença de diversos atores sociais no processo de reaplicação da tecnologia social nos munícípios de Pinhão e Reserva do Iguaçu, observou a ausência de universidades, centros de pesquisas ou institutos federais de educação, seja no processo de desenvolvimento ou reaplicação. As universidades, centros de pesquisas e o meio acadêmico em geral, possuem um papel de grande relevância, no que diz respeito, principalmente, ao desenvolvimento e adaptação dessas tecnologias sociais, unindo o conhecimento científico à sabedoria popular, conforme destacam os estudos de Almeida (2010), Caldas et al. (2007), Dias (2016), Klossowski, Freitas e Freitas (2016), Silva (2012) e Sousa e Rufino (2017).

Ressalta-se também a importância das prefeituras municipais de Pinhão e Reserva do Iguaçu, por meio de suas secretarias de agricultura, no sentido de articular ações e fomentar políticas públicas para o fortalecimento dos projetos da tecnologia social de produção agroecológica, bem como, para os agricultores familiares. A exemplo da Prefeitura de Reserva do Iguaçu, por meio do Programa Hortifruti Mais Orgânico, que incentiva a construção das estufas para a produção de tomates orgânicos. A importância do Estado, por meio dos órgãos das esferas municipais, estaduais e federais, no sentido de criar políticas públicas que viabilizem os projetos de TS, é reafirmado pelos autores Franzoni e Silva (2016), Fonseca e Serafim (2010), De Oliveira e Silva (2012), Gapinski e Freitas (2016).

Nesse sentido, reforçam-se outros exemplos exitosos, tecnologias sociais que se transformaram em políticas públicas e obtiveram grande número de reaplicações na agricultura familiar como o Sistema PAIS - Produção Agroecológica e Integrada e Sustentável, o Programa Um Milhão de Cisternas e o Biodigestor Sertanejo (FBB, 2018).

Cabe salientar ainda que, a exemplo de outras tecnologias sociais, como o Biodigestor Sertanejo, sugere-se a confecção de um manual explicativo para montagem e manutenção da estufa, construção da proteção de fonte e produção de tomates orgânicos, para tornar a tecnologia social acessível a outras famílias e outras localidades do Brasil.

Em resumo, os objetivos da pesquisa foram cumpridos e os resultados podem contribuir para as organizações e os indivíduos analisados na promoção das efetivas ações realizadas, e ainda, no sentido de apoiar o desenvolvimento regional do território Cantuquiriguaçu, baseado na importância e nas ações dos atores sociais tanto no processo de reaplicação e promoção das tecnologias sociais, quanto para outras ações destinadas à agricultura familiar.

\section{REFERÊNCIAS}

ABRANTES, K. K. J. Caminhos estratégicos para o desenvolvimento rural sustentável: uma análise da dinâmica sociotécnica dos quintais produtivos. 2015. 112 f. Dissertação (Mestrado em Economia Agrícola) - Universidade Federal de Ceará, Fortaleza, 2015. 
ABREU, Y. V. et al. Tecnologia apropriada como estratégia de desenvolvimento agrícola: estudo de caso Projeto Quintal Verde - TO. In: 48ํㅡㄴ CONGRESSO DA SOCIEDADE BRASILEIRA DE ECONOMIA, ADMINISTRAÇÃO E SOCIOLOGIA RURAL, 2010, Campo Grande. Anais [...]. Campo Grande: SOBER, 2010. Disponível em: http://sober.org.br/congresso2010/ Acesso em: 10 maio 2018.

ALMEIDA, A. S. A contribuição da extensão universitária para o desenvolvimento de Tecnologias Sociais. Tecnologia social e desenvolvimento sustentável: contribuições da RTS para a formulação de uma política de Estado de Ciência, Tecnologia e Inovação. Brasília/DF: Rede de Tecnologia Social (RTS), p. 9-15, 2010.

AQUINO, R. J.; SCHNEIDER, S. O Pronaf e o desenvolvimento rural brasileiro: avanços, contradições e desafios para o futuro. Políticas públicas de desenvolvimento rural no Brasil. Porto Alegre: Editora da UFRGS, p. 53-81, 2015.

ARAKAKI, A. H. et al. Sistema Integrado de Inovação Tecnológica Social: Programa de Incubação de Empreendimentos Econômicos Solidários EIT-UFMT. Interações, Campo Grande, v. 13, n. 1, 2016.

BALEM, T. A.; ALVES, E. O.; SCHMELING, G. S. Os desafios da produção agroecológica e da construção de uma estratégia de mercado de circuito curto através da entrega domiciliar de produtos. Extensão Rural, Santa Maria, v. 25, n. 4 p. 20-39, out./dez. 2018. Disponível em: https://doi.org/10.5902/2318179634540. Acesso em: 15 jan. 2019.

BARBOZA, R. M. L. T. Estratégias, condições e obstáculos para implantação de técnicas mais sustentáveis no manejo da água em assentamentos rurais. Caso: assentamento rural Horto Vergel "12 de outubro", Mogi-Mirim/SP. 2011. 282 f. Dissertação (Mestrado em Economia Agrícola) - Universidade Federal de São Carlos - UFSCar, São Carlos, 2011.

BONILHA, M. C.; SACHUK, M. I. Identidade e tecnologia social: um estudo junto às artesãs da Vila Rural Esperança. Cadernos EBAPE. BR, v. 9, n. 2, p. 412-437, 2011.

BUGELLI, C. B.; FELÍCIO, J. D. Saneamento rural: a experiência da implementação de uma tecnologia de saneamento no Assentamento Nova São Carlos (São CarlosSP). Revista Tecnologia e Sociedade, v. 15, n. 35, 2019.

CALDAS, A. D. S. et al. Tecnologia Social: cooperação universidade/comunidade para o desenvolvimento urbano regional e local sustentável. RDE - Revista de Desenvolvimento Econômico, v. 9, n.16, p. 16-25, 2007.

CAMPOS, K. C.; CARVALHO, F. M. A. D. Índice de inovação: hierarquização dos produtores do arranjo produtivo local de fruticultura irrigada, estado do Ceará. Revista de Economia e Sociologia Rural, v. 49, n.3, p. 741-770, 2011.

CAMPOS, A. P. T.; SCHMITT, C. J. Rede de relações sociais e arranjos institucionais da agricultura familiar na zona da Mata em Minas Gerais, Brasil: novas formas de governança nas políticas públicas? GIGAPP Estudios Working Papers, v. 4 , n. 72-78, p. 379-398, 2017. 
CARVALHO, E. S.; LAGO, S. M. S. Inovação na agricultura familiar: a apropriação das tecnologias sociais e TICs por produtores familiares. In: $56^{\circ}$ CONGRESSO DA SOCIEDADE BRASILEIRA DE ECONOMIA, ADMINISTRAÇÃO E SOCIOLOGIA RURAL, 2018, Campinas. Anais [...]. Campinas: SOBER, 2018. Disponível em: http://icongresso.itarget.com.br/useradm/anais/?clt=ser.8. Acesso em: 15 jan. 2019.

CARVALHO, E. S et al. Viabilidade e benefícios de implantação de pequenos biodigestores em propriedades de agricultura familiar. In: VI SIMPÓSIO INTERNACIONAL DE GESTÃO DE PROJETOS, INOVAÇÃO E SUSTENTABILIDADE - VI SINGEP, 2017, São Paulo. Anais [...]. São Paulo: UNINOVE, 2017. Disponível em: https://singep.org.br/6singep/resultado/324.pdf. Acesso em: 10 maio 2018.

CARVALHO, D. M. et al. O beneficiamento do amendoim em Ribeirópolis: do trabalho artesanal a aplicação de tecnologia social. Revista GeoNordeste, v. 1, p. 108-131, 2016.

CORDEIRO, K. W. et al. A Tecnologia social e o modo de produção de hortaliças da comunidade Quilombola Chácara Buriti, em Campo Grande - MS. In: 48은 CONGRESSO DA SOCIEDADE BRASILEIRA DE ECONOMIA, ADMINISTRAÇÃO E SOCIOLOGIA RURAL, 2010, Campo Grande. Anais [...]. Campo Grande: SOBER, 2010.

DAGNINO, R. Em direção a uma teoria crítica da tecnologia. Tecnologia social. Ferramenta para construir outra sociedade. 2da ed. Campinas, SP: Komedi, p. 175-220, 2010.

DAGNINO, R. Tecnologia social: base conceitual. Revista Ciência e Tecnologia Social - Observatório do Movimento pela Tecnologia Social da América Latina. v. 1, n. 1, p. 1-12, 2011.

DAGNINO, R. Tecnologia Social: contribuições conceituais e metodológicas [online]. Campina Grande: EDUEPB, 2014. Disponível em: http://books.scielo.org. Acesso em: 15 maio 2018.

DA SILVA, D. B.; DE QUEIROZ CALEMAN, S. M. Sistemas agroindustriais sustentáveis: uma aplicação da economia dos custos de transação. Revista Brasileira de Administração Científica, v. 5, n. 3, p. 287-304, 2014.

DE OLIVEIRA, N. D. A.; SILVA, T. N. Inovação social e tecnologias sociais sustentáveis em relacionamentos intercooperativos: um estudo exploratório no CREDITAG-RO. Revista de Administração da Universidade Federal de Santa Maria, Santa Maria, v. 5, n. 2, p. 277-295, 2012.

DIAS, L. S. O papel da universidade no desenvolvimento de tecnologia sociais: um estudo de caso na UFPE. 2016. 157 f. Dissertação (Mestrado em Administração) - Universidade Federal de Pernambuco - UFPE, Recife, 2016.

DIÓGENES, C. G. B. Caracterização das relações interorganizacionais em tecnologias sociais premiadas pela Fundação Banco do Brasil. 2013. $104 \mathrm{f}$. Dissertação (Mestrado em Administração). Universidade Federal do Paraná. UFPR, Curitiba, Paraná, 2013. 
FARIA, S. S. Adoção de inovações pela agricultura familiar: o caso do cultivo de uvas no estado de Goiás. 2012. 95 f. Dissertação (Mestrado em Ciências Agrárias) Universidade Federal de Goiás, Goiânia, 2012.

FONSECA, R.; SERAFIM, M. A tecnologia social e seus arranjos institucionais. Tecnologia social: ferramenta para construir outra sociedade. Campinas/SP: Komedi, p. 249-264, 2010.

FRAGA, L. Autogestão e tecnologia social: utopia e engajamento. Gestão pública e sociedade: fundamentos e políticas públicas de economia solidária - Volume I. São Paulo: Outras Expressões, p. 101-123, 2011.

FRANZONI, G. B.; SILVA, T. N. Inovação social e tecnologia social: o caso da cadeia curta de agricultores familiares e a alimentação escolar em Porto Alegre/RS. Revista Desenvolvimento em Questão, v. 14, n. 37, p. 353-386, 2016.

FREITAS, C. C. G.; SEGATTO, A. P. Ciência, tecnologia e sociedade pelo olhar da Tecnologia Social: um estudo a partir da Teoria Crítica da Tecnologia. Cadernos EBAPE. BR, v. 12, n. 2, p. 302-320, 2014.

FUNDAÇÃO BANCO DO BRASIL. Banco de Tecnologia Social. FBB. 2018 Disponível em: http://tecnologiasocial.fbb.org.br/tecnologiasocial/principal.htm Acesso em: 10 maio de 2018.

FUNDAÇÃO BANCO DO BRASIL. Banco de Tecnologia Social. Produção Agroecológica sob cultivo protegido (estufa), pomar diversificado e fonte. FBB. 2013. Disponível em: http://tecnologiasocial.fbb.org.br/tecnologiasocial/banco-detecnologias-sociais/pesquisar-tecnologias/detalhar-tecnologia-116.htm. Acesso 12 maio 2018.

GAPINSKI, E. F. P.; FREITAS, C. C. G. Tecnologia social e órgãos públicos municipais: realidades e potencialidades. Revista Tecnologia e Sociedade, v. 12, n. 25, 2016.

GIL, A. C. Métodos e técnicas de pesquisa social. São Paulo: Editora Atlas, 2008.

GRANOVETTER, M. The strength of weak ties: a network theory revisited. Sociological Theory. v. 1. p. 201-233, 1983.

GREGOLIN et al. Potencialidades e fragilidades do Programa Nacional de Alimentação Escolar - PNAE no Território Cantuquiriguaçu (PR). Revista Conexão UEPG, v. 13, n. 3, p. 548-567, 2017.

GRISA, C.; SCHNEIDER, S. Políticas públicas de desenvolvimento rural no Brasil. Porto Alegre: Editora da UFRGS, 2015.

INSTITUTO DE TECNOLOGIA SOCIAL. Conhecimento e cidadania: tecnologia social. ITS Brasil: São Paulo, 2007. Disponível em: www.itsbrasil.org.br. Acesso em: 10 maio 2018.

INSTITUTO PARANAENSE DE DESENVOLVIMENTO ECONÔMICO E SOCIAL. 
Diagnóstico socioeconômico do Território Cantuquiriguaçu. Curitiba: IPARDES, $2007 . \quad$ Disponível em: http://www.ipardes.gov.br/biblioteca/docs/territorio_cantuquiriguacu.pdf. Acesso em: 12 jan. 2019.

KLOSSOWSKI, A.; FREITAS, C. C. G.; FREITAS, F. P. M. O envolvimento da universidade pública em relação à tecnologia social. Revista Tecnologia e Sociedade, v. 12, n. 26, 2016.

LUCENA, T. C. et al. O PNAE e o Sistema de Mandalla no município de Mauriti/CE: No período de 2010 a 2014. Revista Eletrônica Competências Digitais para Agricultura Familiar, v. 3, n. 2, p. 84-95, 2017.

MATTOS, L. C.; FARIAS, M. J. Manual do biodigestor sertanejo. Projeto Dom Helder Camara: 55p, $2011 . \quad$ Disponivel em: https://www.projetodomhelder.gov.br/site/images/PDHC/Artigos_e_Publicacoes/Biodi gestor/Biodigestor_Portugues.pdf. Acesso em: 05 jun. 2018.

MOURÃO, N. M. Tecnologias sociais e empreendimentos criativos na Região Metropolitana de Belo Horizonte/MG. Revista Brasileira de Desenvolvimento Regional, v. 5, n. 1, p. 53-67, 2017.

MUÑOZ, C. M. G. Impactos socioeconômicos e ambientais da tecnologia social de produção agroecológica integrada e sustentável (PAIS) em unidades familiares do Distrito Federal. 2015. 139 f. Dissertação (Mestrado em Agronegócios) - Faculdade de Agronomia e Medicina Veterinária. Universidade de Brasília. (UnB). Brasília, 2015.

NDIAYE, A. Análise do desenvolvimento do programa PAIS - Produção Agroecológica Integrada e Sustentável, enquanto estratégia para geração de renda e segurança alimentar e nutricional de sistemas de produção familiares: estudo realizado nos estados do Rio de Janeiro e Mato Grosso do Sul. 2016. 50 f. Dissertação (Mestrado em Ciências) - Programa de Pós-graduação em Agricultura Orgânica. Universidade Federal Rural do Rio de Janeiro. UFRRJ. Rio de Janeiro, 2016.

NOVAES, H.T; DIAS, R. B. Construção do marco analítico e conceitual da tecnologia social. Tecnologia Social. Ferramenta para construir outra sociedade. 2. ed. Campinas, SP: Komedi, 113-154, 2010.

OLIVEIRA, N. D. A. Desenvolvimento Sustentável, Inovação, Tecnologia Social e Empreendedorismo Coletivo em Relacionamentos Intercooperativos: Sistema CREDITAG e Cooperativas de Produção Agrícola de Rondônia. 2013. 279 f. Tese (Doutorado em Administração) - Universidade Federal do Rio Grande do Sul. UFRGS. Porto Alegre, 2013.

PERERA, A. R. F. Avaliação da rede de referência como estratégia de transferência de tecnologia na perspectiva dos agricultores. 2009. $94 \mathrm{f}$. Dissertação (Mestrado em Sistemas de Produção Agrícola Familiar) - Universidade Federal de Pelotas. UFPEL. Pelotas, 2009. 
RODRIGUES, I.; BARBIERI, J. C. A emergência da tecnologia social: revisitando o movimento da tecnologia apropriada como estratégia de desenvolvimento sustentável. Revista de Administração Pública, v. 42, n. 6, p. 1069-1094, 2008.

SCHNEIDER, S. Reflexões sobre diversidade e diversificação-agricultura, formas familiares e desenvolvimento rural. RURIS-Revista do Centro de Estudos RuraisUNICAMP, v. 4, n. 1, p. 85-130, 2010.

SEBRAE. Sementes do Otimismo. Revista Soluções, n. 13, v. 4, p. 62-65, 2012. Disponível em: http://tecnologiasocial.fbb.org.br/lumis/portal/file/fileDownload.jsp?fileld=8AE389DB3 F67D393013F68074D99221E\&inline=1. Acesso em: 30 mar. 2018.

SILVA, E. O desenvolvimento de tecnologias sociais nas universidades públicas estaduais do Paraná. 2012. 260 f. Tese de Doutorado (Doutorado em Administração) - Universidade Federal do Paraná. UFPR. Curitiba, 2012.

SOUSA, D. S.; RUFINO, S. Tecnologias sociais: panorama da Universidade Federal do Rio Grande do Norte. Revista Tecnologia e Sociedade, v. 13, n. 29, 2017.

ZYLBERSZTAJN, D. Papel dos contratos na coordenação agroindustrial: um olhar além dos mercados. Revista de Economia e Sociologia Rural, v. 43, n. 3, p. 385420, 2005. 